The final, published version of this article is available at https://www.karger.com/Article/Abstract/513928 or https://doi.org/10.1159/000513928 


\section{Research Article \\ Effects of Finding the Speech-Language Pathologist Likeable on Postlaryngectomy Speech Intelligibility Outcomes}

Marlies Feiner MSc ${ }^{1}$, Judith Keszte MSc ${ }^{2}$, Alexandra MeyerPhD ${ }^{3}$, Stefan T. Kulnik PhD ${ }^{4,5}$, Martin Maasz MBA ${ }^{5}$, Harald Lothaller $\mathrm{PhD}^{6}$, Michael Fuchs $\mathrm{MD}^{7}$, Karl Hormes $\mathrm{MSc}^{8}$, Jens Oeken MD ${ }^{9}$, HansJoachim Vogel MD ${ }^{10}$, Sven Koscielny MD ${ }^{11}$, Friedemann Pabst MD ${ }^{12}$, Susanne Singer PhD ${ }^{13,14}$

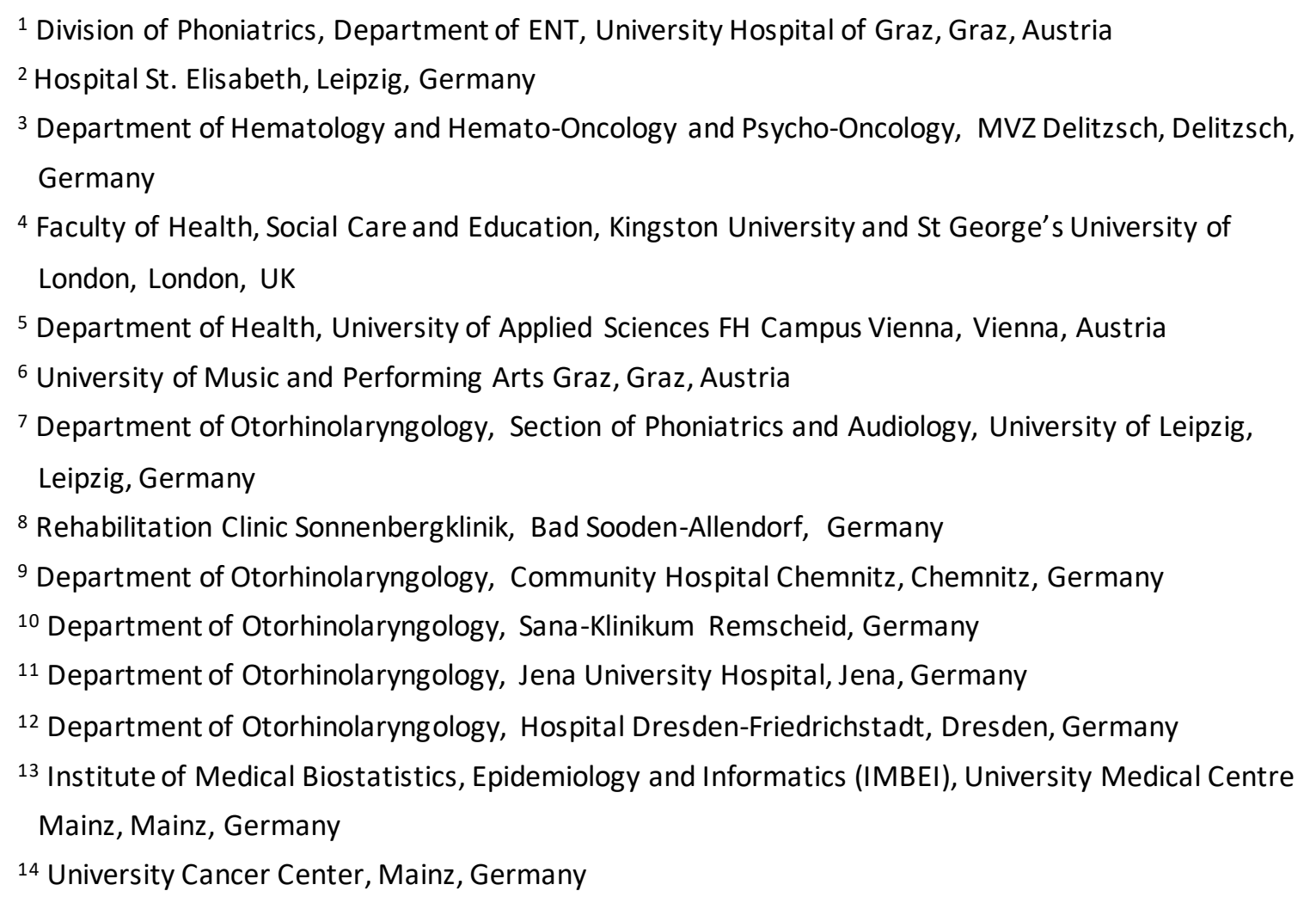

Short Title: Effects of SLPs' likeability on speech rehabilitation

Corresponding Author:

Marlies Feiner

Department of Phoniatrics, ENT University Hospital of Graz

Auenbruggerplatz 26

Graz, 8036, Austria

telephone: +43(316) 385 - 81559

email: marlies.feiner@klinikum-graz.at 
Number of Tables: 2

Number of Figures: 1

Word count: 4436

Keywords: total laryngectomy; speech-language pathology; therapeutic relationship; speech intelligibility; patient-reported outcomes 


\begin{abstract}
Introduction

Speech-Language Pathologists (SLPS) work with patients after total laryngectomy (TL) to regain verbal communication. The influence of the quality of the therapeutic relationship on the succes s of TL voice rehabilitation in terms of speech intelligibility is not known. Finding each other likeable is an important factor in establishing and maintaining interpersonal relationships in everyday life. The fit of therapist and client is relevant to the therapeutic relationship. The purpose of this study therefore was to assess the association between the degree of SLPs' likeability ratings and postlaryngectomy speech intelligibility.

\section{Methods}

In a multicentre prospective cohort study, participants rated their SLPs' likeability after finishing TL rehabilitation. Speech intelligibility was measured objectively with the Post-Laryngectomy Telephone Intelligibility Test and subjectively with the Questionnaire for Adjustment after Laryngectomy. Association of SLPs' likeability with speech intelligibility was analysed using hierarchical logistic regression, expressed with odds ratios (OR) with corresponding 95\% confidence intervals (Cl).

\section{Results}

Altogether 124 patients from 13 institutions participated. The degree of finding the SLP likeable was not significantly associated with objective speech intelligibility (OR 1.30; $\mathrm{Cl} 0.78-2.18 ; \mathrm{p}=.32$ ) or subjective speech intelligibility (OR 1.01; $\mathrm{Cl}, 0.60-1.72 ; \mathrm{p}=.96)$ after controlling for age, sex and education factors.

\title{
Discussion/Conclusion
}

In this patient cohort, there was no evidence for an association between ratings of SLPs' likeability and speech intelligibility outcomes after rehabilitation. Future studies could consider the use of alternative instruments for measuring likeability. 


\section{Introduction}

The altered anatomy after total laryngectomy (TL) leads to extensive functional changes. Past research results have recorded patients' experiences of physical symptoms and communicative impairment, as well as psychological concerns following TL [1-3]. Changes affect body functions and structures, for example alaryngeal speech, daily activities such as bathing, societal participation such as communicating at social events, and contextual factors, including stigmatization [4].

Speech-language pathologists (SLPS) are trained in teaching substitute voice techniques. Hence, they work frequently in the field of laryngectomy rehabilitation [5]. Therapy options for substituting laryngeal phonation include the use of a tracheoesophageal prosthesis, producing oesophageal voice, and the use of an electronic device. Tracheoesophageal prosthesis is advantageous with regards to acoustic and perceptual outcomes; but patient-reported outcomes do not favour one of the three methods [6]. Helping the patients choose between the best voice technique or techniques for them has to be done by considering the patient's individual anatomical, cognitive and social conditions, and personal needs [7]. Thus, the SLPs' work not only focusses on voice restoration, but also concerns choosing appropriate communication techniques in certain situations [8], as well as other aspects such as self-perception, breathing, posture, articulation, or a new technique for whispering [9]. In Germany, treatment conducted by SLPs usually starts with a preoperative consultation and postoperative patient contact in the clinic. The voice rehabilitation can continue with an inpatient rehabilitation stay (follow-up treatment) for typically three weeks, where extension is possible. Inpatient rehabilitation treatment includes, for example, physiotherapy, nutritional advice and consulting service besides speech and language therapy. Patients are entitled to a further inpatient rehabilitation stay within the next two years. In addition, therapy sessions in outpatient speechlanguage pathology practices, and home visits are possible [10].

Factors associated with successfulvoice rehabilitation after TL were summarized in a systematic review of 24 studies [11]. Among the factors identified to be relevant for successfulvoice rehabilitation after TL were sociodemographic, psychosocial, and treatment-related factors. Patients' age $[12-16]$ and education level $[15,17,18]$ affect therapy success. Furthermore gender differences in experiencing total laryngectomy were also reported $[1-3,19]$, which then may affect subjective satisfaction with rehabilitation outcome.

As a treatment-related factor the impact of speech and language therapy on TL rehabilitation has been studied before $[15,20,21]$, although the specific components of treatment delivery may have differed across studies. Singer et al. [11] evaluated the outcomes of six studies of speech and language therapy after TL. Results reported were mixed; three studies showed positive correlations, 
two studies reported no correlations and one study demonstrated a negative correlation of speech and language therapy with successful voice rehabilitation. Another study found that the duration of voice rehabilitation had a positive impact on mastering oesophageal speech [15]. Speech intelligibility was better in patients who attended rehabilitation whatsoever compared to those patients who received no rehabilitation [17]. These findings relate to speech-language pathology as a whole.

To integrate the principles of evidence-based practice, it is of interest to examine the various components of speech and language therapy as a complex intervention, to better understand its "active ingredients" [22]. To date, speech and language therapy outcome research has focused mainly on the impact of technical aspects, rather than on the impact of the therapeutic relationship [23]. But there is a growing corpus of literature on the concepts "therapeutic relationship" or "therapeutic alliance", that aims to better understand their impact on outcomes and adherence in speech-language pathology.

The therapeutic relationship is important throughout the whole therapy process (e.g. incorporating patient's perspectives in diagnostics, setting goals which are meaningful for the patient, participation in the therapy process and adjusting to the therapy process). Thus, it can be emphasized that the therapeutic relationship is important for the progress and results of speech and language therapy [24]. Along these lines, Lambert and Barley present a model, which estimates the relative contributions of four specific therapeuticfactors towards client outcome in psychotherapy. The model states that $30 \%$ of the improvement as a result of therapy relate to factors involving the therapeutic relationship and therapist variables, which are common in most therapy settings [25]. This model was originally developed for psychotherapy outcome research, but it may also be applied in speech-language pathology [26], since methodical approaches from psychotherapy research hold links to speech-language pathology research [24] and theory from psychotherapy research is applied to inform research and practice [27].

Results from qualitative research suggest that treatment efficacy in speech-language pathology can not only be explained by the association of methods and outcomes, but can also be partly explained by factors of the therapeutic relationship. Patients in speech and language therapy, occupational therapy and physiotherapy evaluate the success of the therapy based on the improvement in their symptoms associated a with a feeling of being accepted as a person and perception of the therapists' empathy [28]. Eleven participants experiencing communication and swallowing disorders in a study by Fourie et al. described SLPs' contributions to a therapeutic relationship from their perspective. The restorative poise consisted of certain therapeutic qualities (SLPS being understanding, gracious, 
erudite and inspiring) and therapeutic actions (SLPs enacting therapy in a confident, soothing, practical and empowering way). These components were important to participants' understanding of positive therapy outcome [29].

Beier discusses the connection between specific variables that take effect an d unspecific variables that enable treatment to be effective in speech language pathology. Treatment adherence in speech and language therapy may be influenced by the effective treatment method, contextual factors, meaningfulness of therapy goals and the therapist-patient-relationship [30]. A good relationship with the speech-language pathologist (SLP) is recognised as a facilitator to adherence in behavioural voice therapy. It also helps patients to cope with the barrier of feeling silly in voice exercises [31]. There is also evidence of the influence of the therapeutic relationship on engagement, which is described both as a patient's internal state and a gradual connection between therapist and patient. Hence, the influence of clinicians and SLPs is critical in promoting patient engagement $[32,33]$.

The term "therapeutic alliance" is partly understood as one factor in the therapeutic relationship [25], but is partly also used synonymously with "therapeutic relationship" [34]. The therapeutic alliance or working alliance represents "a proactive collaboration of clients and therapists across treatment sessions" [27] and may also have an effect on treatment adherence and engagement [35]. The dimensions of the therapeutic alliance identified by Bordin are the agreement on the goal of treatment, agreement and collaboration on tasks and the emotional bond between client and therapist [36]. Research has been done on the influence of the therapeuticalliance in speech and language therapy. In a study with 28 adults who received speech therapy for stuttering, SLPs were experienced as more effective in improving a client's ability to communicate, when they could form a positive therapeutic alliance. Attributions of effective SLPs among others were, being passionate and client-centred and seeing the patient as a whole person. A positive therapeutic alliance was important for participants' motivation for therapy [37]. This is supported by findings from another work group showing associations between client motivation and treatment outcomes and the working alliance in 18 people who stutter [27]. In a qualitative study involving 18 participants suffering from aphasia, results demonstrate that a good alliance has a positive effect on adherence and hope, and ineffectual alliances have a negative effect on engagement [34].

Finding each other likeable is an important factor of human social life in general. In social psychology it plays a role in several areas (e.g. in social perception or in group formation) [38]. It is also a fundamental factor of all therapeutic relationships [39]. Bordin states that "Strength of alliance will be a function of the goodness of fit of the respective personalities of patient and therapist to the demands of the working alliance"[36]. In an evaluation of motivational factors for the comparable 
discipline physiotherapy, all six participants emphasized the importance of the level of finding their physical therapist likeable for preserving motivation throughout the course of therapy [40]. Already at the first meeting of speech therapist and patient, a likeable, not likeable, ambivalent or indecisive impression may arise [41]. In the course of therapy transference can influence finding the SLP likeable [42]. In agreement with Bordins findings, a qualitative analysis underlined the importance of the SLP and the patient being a good match in voice therapy. Within the same treatment approach, patients individually showed a strong preference for one therapist over another [31].

We have not identified studies addressing the therapeutic relationship or its components in the field of speech-language pathology rehabilitation after TL. The present work should serve as a first step towards exploring one of the components of the therapeutic relationship in the area of TL rehabilitation. This study aimed to examine the association of finding the SLP more or less likeable with subsequent speech intelligibility considering influencing factors. Our research question was: Is the degree of finding the SLP likeable associated with speech intelligibility at the end of inpatient laryngectomy rehabilitation?

\section{Materials and Methods}

\section{Study design, participants and data collection}

We conducted a multicentre prospective cohort study and enrolled participants consecutively from September 2001 to January 2009 from 13 German clinics. Our research team was informed when total laryngectomy was planned for a patient. Patients were then con tacted and informed about the study verbally and in writing by our researchers. All study participants gave written informed consent. All procedures performed in this study involving human participants were in accordance with the ethical standards of the ethical board of the Medical Faculty of University of Leipzig, Germany.

Data collection visits took place before $\mathrm{TL}(\mathrm{t} 1$ ), at the start of rehabilitation ( $\mathrm{t} 2$ ) and after rehabilitation had ended ( $\mathrm{t} 3$ ). Participants underwent structured face-to-face interviews at all time points, either in the clinic or at the participants' home. These face-to-face interviews helped motivation to participate. Interviews were conducted by trained psychologists and student researchers. Researchers were supervised every 2 weeks to ensure objectivity. None of the assessments was carried out by the SLPs administering treatment. Questions asked were related to medical and psychosocial rehabilitation. In addition, mental health was evaluated using a structured clinical interview and voice intelligibility was tested. Participants also completed self-administered 
questionnaires. For the current analysis, we excluded all patients who had not received any speech and language therapy in inpatient rehabilitation until $\mathrm{t} 3$.

\section{Instruments and variables}

There are various outcome criteria for speech and language therapy after TL. Because speech and language therapy in laryngeal cancer provides initial treatment but also long-time care [5], short- and long-term treatment effects need to be evaluated. Furthermore, it should be considered that subjective intelligibility ratings by patients may differ from subjective ratings by SLPs [43], patient's relatives [44], and other listeners [45]. Therefore, it is recommended that speech intelligibility is measured both objectively and subjectively [11].

\section{Speech intelligibility}

Our study assessed both objective and subjective speech intelligibility at $\mathrm{t} 3$ as indicators of voice rehabilitation outcome. Objective speech intelligibility was captured using the standardized PostLaryngectomy Telephone Intelligibility Test (PLTT) $[10,46,47]$ that measures speech intelligibility by telephone. This test has confirmed reliability and validity $[46,47]$. The laryngectomized person speaks twenty monosyllables and five sentences randomly chosen from an existing corpus of items into a telephone without visual contact with the examiner. The method of alaryngeal speech can be chosen freely by the participant. The examiner writes down the understood monosyllables and sentences and subsequently enters any deviations in the comparison to the items on the PLTT-form.

PLTT results range from zero to 100 with higher values indicating better speech intelligibility. No common categorization for the results could be identified in our literature research. For our study, we favoured an allocation in two groups, a group with no objective speech intelligibility (PLTT result 0 , or carrying out PLTT not possible) and a group with low to high objective speech intelligibility (PLTT results $>0)$.

Subjective speech intelligibility was measured with a question taken from the Questionnaire for Adjustment after Laryngectomy (FPAL), a self-reported German instrument with 124 items [48]. Participants were asked to rate their speech intelligibility as specified by the questionnaire. Response 
options included (1) very good, (2) good, (3) satisfying, (4) sufficient, (5) insufficient and (6) poor. We dichotomized subjective speech intelligibility into low (rating 5 and 6) versus high (rating 1-4).

\section{Client-SLP factors}

We asked the participants in the structured interview at $\mathrm{t} 3$ how likeable they found their SLP in inpatient rehabilitation on a five-point Likert scale. Response options were (1) extremely likeable, (2) very likeable, (3) likeable, (4) unlikeable and (5) not at all likeable.

\section{Client factors}

Demographic information including the age, sex, and educational level of each participant was collected at $\mathrm{t} 1$ and $\mathrm{t} 2$ in structured interviews. If age was missing for a participant, the group's mean age was used in the regression analysis. Educational level was dichotomized into compulsory level versus above.

Clinical data including the length of inpatient rehabilitation and communication techniques, were obtained in the interview or from the medical records by the researchers.

\section{Statistical analysis}

Descriptive statistics for the sample were calculated using percentage, mean and standard deviation as well as range, median and interquartile range (IQR). We conducted a multivariate analysis to examine the impact of perceiving the SLP to be more or less likeable on successfulvoice rehabilitation, and to control for the impact of other relevant variables. For both outcomes, objective and subjective speech intelligibility, logistic hierarchical regressions were performed [49]. In both models, variables were successively entered within two blocks: (1) client-SLP factors and (2) client factors (shown in Figure 1), derived from our model. This model was created based on clinical experience and evidence from the literature [25]. We chose the variables to be considered most important while leaving out other variables, to create a parsimonious model that has enough power to be tested with the given sample size. SPSS software version 24 (2016, IBM) was used for all data analyses.

\section{Results}

\section{Participants}

We contacted 473 individuals with planned TL at t1. At t3, 273 individuals of the contacted 473 participants were interviewed. Of the remaining 200 patients, 12 could not be located, 46 eventually did not undergo TL, 17 could not be interviewed at this time point, 20 had died, and 105 declined to participate in the interview. Of the 273 participants who were interviewed at 13,209 had attended 
inpatient rehabilitation and 202 of them had received speech and language therapy in this setting. From the 202 participants that had received inpatient speech and language therapy, a total of 124 provided data on all items relevant for the analysis, including objective and subjective measurement of speech intelligibility and likeability ratings for their SLP. These 124 participants were included in the data analysis for this study.

Among the participants, 110 (89\%) were male. The mean age was 57 years (SD, 9.81; range, 26-75 years). Age was missing for 8 of the 124 participants in our cohort, for which mean age was used as replacement value. Forty-four percent of participants $(n=54)$ had an educational level above compulsory level. One hundred and eleven individuals (90\%) were treated with neck dissection. The start of inpatient rehabilitation was on average 13.4 weeks after TL surgery (SD, 7.3; $n=123$ ). The mean duration of in patient rehabilitation was 3.7 weeks (median, 3 weeks; range, 3-7weeks; data available for $n=74$ ). Most participants were offered speech and language therapy on a daily base (66 $\%$ ) or several times a week (32\%), only three participants attended weekly speech and language therapy sessions ( $2 \%)$. The communication techniques used in daily life can be found in table 1.

\section{Speech intelligibility}

The mean PLTT score was 31 (range, 0-100; median, 16; IQR, 59). Fifty-seven percent ( $n=71)$ of participants were grouped into low to high objective speech intelligibility based on their PLTT scores of $>0$. They freely chose the type of voice used in the test ( $30 \%$ tracheoesophageal prosthesis, $14 \%$ electronic device, $14 \%$ oesophageal voice, $1 \%$ whispering using the air in the mouth). Forty-two percent $(n=52)$ of participants were not able to speak in the test.

When all the participants were asked about their subjective speech intelligibility, three participants (2\%) rated their speech intelligibility as very good; 21 (17\%) said it was good, 33 (27\%) said it was satisfying and 27 (22\%) said their speech inte lligibility was sufficient. Twenty-four individuals (19\%) rated their speech intelligibility as insufficient and 16 participants (13\%) said it was poor. Hence, 40 participants (32\%) had low and 84 participants (68\%) high subjective speech intelligibility.

\section{Client-SLP factors}

Approximately one third $(n=39 ; 32 \%)$ of all participants rated their SLP to be extremely likeable; nearly half of the participants $(n=58 ; 47 \%)$ rated the SLP as very likeable; $26(21 \%)$ said their SLP was likeable and one participant (1\%) rated the SLP as unlikeable. None of the participants said their SLP was not at all likeable. 


\section{Associations with objective speech intelligibility}

The degree of finding the SLP likeable was not significantly associated with objective speech intelligibility ( $\mathrm{OR}, 1.30 ; 95 \% \mathrm{Cl} 0.78-2.18 ; \mathrm{p}=.32$ ). Client factors were controlled, as can be seen in table 2. We found the overall model to be statistically significant $(\chi 2=14.07 ; p<0.007$ with a Nagelkerkes R20.14). The overall model predicted $62 \%$ of cases correctly.

\section{Associations with subjective speech intelligibility}

There was no statistically significant evidence that finding the SLP likeable was associated with subjective speech intelligibility ( $\mathrm{OR}, 1.01 ; 95 \% \mathrm{Cl}, 0.60-1.72 ; \mathrm{p}=.96)$. Table 2 gives an overview of $\mathrm{OR}$ and $\mathrm{Cl}$ for the single factors in the final model. We did not find the overall model to be statistically significant ( $\chi 2=7.19 ; p<.126 ;$ Nagelkerkes R2 0.08 ), and 65\% of cases were correctly predicted.

\section{Discussion/Conclusion}

We aimed to examine the association of one specific factor of the therapeutic relationship on voice rehabilitation outcome after TL, namely finding the SLP likeable. Our study cohort consisted of 124 participants that received speech and language therapy in inpatient rehabilitation following TL. Participants were interviewed in person and tested by novel listeners after completion of inpatient rehabilitation. In this study we could not find evidence for an association between the degree to which participants find their SLP likeable and successful voice rehabilitation. This was consistent for both objective and subjective speech intelligibility measures.

A potential explanation for this finding may be that both the predictor of interest as well as the outcomes were assessed at the same time point. On the one hand, this was necessary because participants needed to experience their relationship with the SLP prior to assessing it. On the other hand, this methodological approach makes it difficult to disentangle coping processes from "real" effects of the therapeutic relationship.

Second, the handling of missing data could have reduced the power of our analyses, so we might have missed an existing effect. We decided a priori to include only those participants who had a complete dataset concerning likeability ratings and both outcome parameters. We did not compute replacement values for these missing data sets, since we used binary outcome variables in our regression model, for which we did not regard computed replacement values as meaningful. We also decided against computing replacement values for likeability ratings as the predictor of interest. Other limitations that should be mentioned here are that we did not check whether all therapy units were continuously carried out by the same speech therapist, and we did not obtain the number of 
speech and language therapy sessions received prior to inpatient rehabilitation. A limitation in carrying out the PLTT is, that we did not screen the hearing of our researchers prior to the intelligibility assessments. Another limitation to data collection in the PLTT is, that we did not record the words and phrases spoken in the PLTT assessment, therefore an analysis of interrater coefficients for more than one rater could not be done.

Finally, our results showed a skewed distribution of finding the SLP likeable. This may have been influenced by limitations of our five-point Likert scale which contained only two "negative" rating options and three "positive" rating options, and was therefore slightly weighted towards "positive" ratings. We had decided to add an extreme option in the response categories in order to gain larger variance. It should be noted that ratings were made verbally in a structured interview with a member of the research team. None of the interviews and assessments was obtained by the treating SLPS. Although participants were informed about the confidentiality of ratings and anonymization of results, the setting might have led to socially desirable response behaviour. Participants' dependence on speech-language pathology services or lack of previous knowledge and possibility of comparison of the service may also have led to higher likeability ratings.

"Common factors" in the therapy setting are subject to constant changes in the course of therapy and to interdependencies (with e.g. the health care system and society) [30]. The duration of the therapeutic relation in inpatient rehabilitation is limited because the usual stay in a clinic is 3 to 4 weeks. This may also be a reason for the small effect sizes we found. Nonetheless, working alliance perception appears to be particularly important at an early stage in speech and language therapy. In aphasia therapy, the alliance thrived as therapy progressed, provided the short-term alliance was good [34]. In treatment of stuttering, a positive working alliance at the start of treatment was associated with positive treatment results [27].

Theoretically, we partly based our assumption of the importance of the therapeutic relationship and likeability of a therapist on results of psychotherapy research, since some authors suggest the results to be applicable to speech and language therapy $[24,26,27,31]$. However, although both therapy disciplines operate as complex interventions, comparability may be limited, in particular with respect to the highly specialized area of speech-language pathology in TL rehabilitation.

Interventions in rehabilitation are often characterized as a "black box" [50] and it can be difficult to identify the "active ingredients" of treatment interventions [22]. In doing so, speech-language pathology research often focusses on technical aspects [23] As a result, the cultivation and perception of therapeutic relationships in speech-language pathology is under-researched [29]. In the present study, we aimed to investigate finding the SLP likeable as one component of the 
therapeutic relationship in postlaryngectomy speech and language therapy as opposed to the methodical technical elements of the therapy intervention.

We identified research on the therapeutic relationship in speech-language pathology $[27,29,31,34,37]$ and taxonomy of voice therapy [51], but none of these studies specifically addressed TL rehabilitation in detail. Previous studies concerning speech-language pathology after TL identified in a review paper [11] have focused on the speech-language pathology intervention as a whole, instead of single factors of the intervention. Recent studies showed a positive influence of speech rehabilitation on quality of life [20] and a reduced length of hospital stay and readmissions in association with preoperative consultation with a SLP [21]. Similar to our results which showed no association between the degree to which participants found their SLP likeable and speech intelligibility, patients' motivation to gain a new voice was not a strong predictor of speech intelligibility in TL rehabilitation [17].

Although there was no evidence for an association between speech intelligibility and participants' likeability ratings for their allocated SLPs in our study, likeability ratings are nevertheless of interest. The evidence based practice model places high importance on client values and preferences [52], and therefore these should always be taken into consideration in therapy evaluation. There might be unique patient preferences concerning the therapist. Fourie suggests "how the therapist constructs such a relationship with a client is highly meaningful to the client and may help resolve various existential crises evoked by the client in response to a communication disorder" [29]. Only one of our participants rated his SLP to be unlikeable. All other participants reported their SLP was likeable to different degrees. This indicates a positive appraisal of the construct of finding the SLPs likeable in our inpatient rehabilitation cohort. The positive ratings can be seen as relevant feedback on current rehabilitation for clinicians and policymakers.

Further research on the influence of finding the SLP likeable as a predictive factor may focus on other aspects or concepts of likeability, or assess this with a standardized measures. Finding the SLP likeable may have a different weight in other patient phenotypes or on other outcomes like engagement, adherence or hope. Also, qualitative approaches may allow deeper insights in the concept of finding the therapist likeable as well as in the therapeutic relationship in general and its elements. If future studies achieve more variance in the ratings for finding the SLP likeable, the formation for subgroups for client factors (e.g. age, sex, educational level) could be of interest. Another possibility for further research might be the use of categories other than "finding the SLP likeable" to examine the quality of the therapeutic relationship that may have more weighting (for example perceiving the SLP as understanding, gracious, erudite or inspiring). There is a continuous 
need to investigate the active ingredients of the "black box" of rehabilitation treatment interventions in general, and also for rare conditions such as total laryngectomy, so that rehabilitation may increase in efficacy. 


\section{Statements}

\section{Statement of Ethics}

All procedures performed in this study involving human participants were in accordance with the ethical standards of the ethical board of the Medical Faculty of University of Leipzig, Germany (reference number 164/2005) and the World Medical Association Declaration of Helsinki. Written informed consent was obtained from all individual participants included in the study.

\section{Conflict of Interest Statement}

The authors have no conflicts of interest to declare.

\section{Funding Sources}

This study was supported by grants from the German Federal Ministry of Education and Research (\#7DZAIQTX) and the German Cancer Aid (\#106654). 


\section{Author Contributions}

S. Singer, J. Keszte, M. Feiner and A. Meyer conceived of the presented idea. M. Fuchs, K. Hormes, J. Oeken, H-J. Vogel, S. Koscielny and F. Pabst were involved in carrying out the data collection. S. Singer encouraged M. Feiner to investigate likea bility as an influencing factor in speech rehabilitation, supervised the work and contributed to the interpretation of the results together with S.T. Kulnik and M. Maasz. The development of the theoretical formalism and analytic calculations was performed by H. Lothaller and M. Feiner. M. Feiner took the lead in writing the manuscript. All authors provided critical feedback and helped shape the research, analysis and manuscript. 


\section{References [Numerical]}

1 Bickford J, Coveney J, Baker J, Hersh D. Living with the altered self: A qualitative study of life after total laryngectomy. Int J Speech Lang Pathol. 2013;15(3):324-33. Noonan BJ, HegartyJ. The impact of total laryngectomy: The patient's perspective. Oncol Nurs Forum. 2010;37(3):293-301.

Dooks P, McQuestion M, Goldstein D, Molassiotis A. Experiences of patients with laryngectomies as they reintegrate into their community. Support Care Cancer. 2012;20(3):489-98.

Eadie TL. Application of the ICF in communication after total laryngectomy. Semin Speech Lang. 2007;28(4):291300.

Starmer HM, Quon H, Simpson M, Webster K, Tippett D, Herbert RJ, et al. Speech-language pathology care and short- and long-term outcomes of laryngeal cancer treatment in the elderly. Laryngoscope. 2015 Dec;125(12):2756-63. van Sluis KE, van der Molen L, van Son RJJH, Hilgers FJM, Bhairosing PA, van den Brekel MWM. Objective and subjective voice outcomes after total laryngectomy: a systematic review. Eur Arch Oto-Rhino-Laryngology. 2018 Jan;275(1):11-26. Marek A. Psychosoziale Rehabilitation nach Laryngektomie. Psychosomatik in der HNO-Heilkunde. Stuttgart: Thieme; 2009; p p 124-128. de Maddalena H. Kommunikationstraining für Laryngektomierte. In: Grohnfeldt M, editor. Handbuch der Sprachtherapie Band 7. Stimmstörungen. Berlin: Edition Marhold; 1994; p p 356-369. Dicks P. Laryngektomie: Logopädische Therapie bei Kelkopflosigkeit. Idstein: Schulz-Kirchner; 2007. Glunz M, Reuß C, Schmitz E, Stappert H. Laryngektomie. Von der Stimmlosigkeit zur Stimme. 2nd ed. Berlin: Springer; 2011. Singer S, Merbach M, Dietz A, Schwarz R. Psychosocial determinants of successful voice rehabil itation after laryngectomy. J Chinese Med Assoc. 2007 Oct;70(10):407-23. Mäkitie AA, Niemensivu R, Juvas A, Aaltonen L-M, Bäck L, Lehtonen H. Postlaryngectomy voice restoration using a voice prosthesis: A single institution's ten-year experience. Ann Otol Rhinol Laryngol. 2003 Dec;112(12):1007-10. Woodard TD, OplatekA, Petruzzelli GJ. Life After Total Laryngectomy. A Measure of Long-term Survival, Function, and Quality of Life. Arch otolaryngol head neck surg. 2007 Jun;133(6):526-32. Frith C, Buffalo MD, Montague JC. Relationships between esophageal speech proficiency and surgical, biographical, and social factors. J Commun Disord. 1985;18(6):475-83. Sokal W, Kordylewska M, Golusiński W. An influence of some factors on the logopedic reha bilitation of patients after total laryngectomy [Abstract]. Otolaryngol Pol. 2011;65(1):20-5. Jacobson MC, Franssen E, Birt BD, Davidson MJ, Gilbert RW. Predicting postlaryngectomy voice outcome in an era of primary tracheoesophageal fistulation: A retrospective evaluation. J Otolaryngol. 1997;26(3):171-9. Singer S, Meyer A, Fuchs M, Schock J, Pabst F, Vogel H-J, et al. Motivation as a predictor of speech intelligibility 
after total laryngectomy. Head Neck. 2013 Jun;35(6):836-46.

Keith RL, Ewert JC, Flowers CR. Factors influencing the learning of esophageal speech. Br J Disord Commun. 1974 Oct;9(2):110-616.

Smithwick L, Davis P, Dancer J, Hicks GS, Montague J. Female laryngectomees' satisfaction with communication methods and speech-language pathology services. Percept Mot Skills. 2002;94:204-6.

Pereira Da Silva A, Feliciano T, Vaz Freitas S, Esteves S, Almeida E Sousa C. Quality of life in patients submitted to total laryngectomy. J Voice. 2015;29(3):382-8.

Shenson JA, Craig JN, Rohde SL. Effect of preoperative counseling on hospital length of stay and readmissions after total laryngectomy. Otolaryngol Neck Surg. 2017 Feb;156(2):289-98.

Whyte J, Dijkers MP, Hart T, Zanca JM, Packel A, Ferraro M, et al. Development of a theory-driven rehabilitation treatment taxonomy: Conceptual issues. Arch Phys Med Rehabil. 2014 Jan;95(1):24-32.

Maihack V, Baumgartner S. Sprachtherapie - Wissenschaftlichkeit, Methodik, Praxis. In: Grohnfeldt M, editor. Grundwissen der Sprachheilpädagogik und Sprachtherapie. Stuttgart: Kohlhammer; 2014; p p 54-67.

Hansen H. Kooperation in der Sprachtherapie. In: Grohnfeldt M, editor. Kompendium der akademischen Sprachtherapie und Logopädie. Band 1: Sprachtherapeutische Handlungskompetenzen. Stuttgart: Kohlhammer; 2016; p p 213-231.

Lambert MJ, Barley DE. Research summary on the therapeutic relationship and psychotherapy outcome. In: Norcross JC, editor. Psychotherapy relationships that work. Therapist contributions and responsiveness to patients. Oxford: University Press; 2002; p p 17-32.

Grohnfeldt M. Lexikon der Sprachtherapie. Stuttgart: Kohlhammer; 2007.

Sønsterud H, Kirmess M, Howells K, Ward D, Feragen KB, Halvorsen MS. The working alliance in stuttering treatment: a neglected variable? Int J Lang Commun Disord. 2019;54(4):606-19.

Dehn-Hindenberg A. Patientenbedürfnisse in der Physiotherapie, Ergotherapie und Logopädie. Idstein: SchulzKirchner-Verlag; 2008.

Fourie RJ. Qualitative study of the therapeutic relationship in speech and language therapy: Perspectives of adults with acquired communication and swallowing disorders. Int J Lang Commun Disord. 2009 Jan;44(6):979-99.

Beier J. Zur Beziehung von Befund und Befinden in der evidenzbasierten Logopädie - ein Plädoyer für die Betrachtung allgemeiner Wirkfaktoren. Evidenzbasierte Praxis in den Gesundheitsberufen. Berlin, Heidelberg: Springer Berlin Heidelberg; 2018; pp 197-214.

van Leer E, Connor NP. Patient perceptions of voice therapy adherence. J Voice. 2010 Jul;24(4):458-69.

Bright F. Reconceptualising engagement: A relational practice with people experiencing communication disability after stroke. 2015Available from: http://aut.researchgateway.ac.nz/handle/10292/9754 Bright FAS, Kayes NM, Worrall L, McPherson KM. A conceptual review of engagement in healthcare and rehabilitation. Disabil Rehabil. 2015 Apr;37(8):643-54. 
aphasia rehabilitation post stroke: a thematic analysis. Aphasiology. 2018 Dec;32(12):1397-417.

Lawton M, Sage K, Haddock G, Conroy P, Serrant L. Speech and language therapists' perspectives of therapeutic alliance construction and maintenance in aphasia rehabilitation post-stroke. Int J Lang Commun Disord. 2018;53(3):550-63.

Bordin ES. The generalizability of the psychoanalytic concept of the working alliance. Psychother Theory, Res Pract. 1979;16(3):252-60.

Plexico LW, Manning WH, DiLollo A. Client perceptions of effective and ineffective therapeutic alliances during treatment for stuttering. J Fluency Disord. 2010;35(4):333-54.

Werth L, Mayer J. Sozialpsychologie. Berlin Heidelberg: Springer; 2008.

Senf W, Broda M, Wilms B. Therapeutische Beziehung. In: Senf W, Broda M, editors. Praxis der Psychotherapie: Ein integratives Lehrbuch. , 5th ed. Stuttgart: Thieme; 2012; p p 105-111.

Rucker A, Baier J. Motivationsfaktoren für Physiotherapie aus der Sicht des Patienten. physioscience. 2012 Nov;8(04):163-8.

Tuschy-Nitsch D. Weichen stellen: Was geschieht bei der ersten Begegnung? In: Spiecker-Henke M, editor. Leitlinien der Stimmtherapie. Stuttgart: Thieme; 1997; pp 43-5.

Spiecker-Henke M. Übertragung und Abwehr: Autorität und Sympathie. In: Spiecker-Henke M, editor. Leitlinien der Stimmtherapie. Stuttgart: Thieme; 1997; pp 51-3.

Cantu E, Ryan J, Tansey S, Johnson CS. Tracheoesophageal speech: Predictors of success and social validity ratings. Am J Otolaryngol. 1998;19(1):12-7.

Schuller DE, Trudeau M, Bistline J, LaFace K. Evaluation of voice by patients and close relatives following different laryngeal cancer treatments. J Surg Oncol. 1990;44(1):10-4.

Eadie TL, Otero D, Cox S, Johnson J, Baylor CR, Yorkston KM, et al. The relationship between communicative participation and postlaryngectomy speech outcomes. Head Neck. 2016 Apr;38(S1):E1955-61.

Zenner HP, Pfrang H. Ein einfacher Sprachverständlichkeitstest zur Beurteilung der Stimmrehabilitation des Laryngektomierten. Laryngol Rhinol Otol. 1986;65:271-6.

de Maddalena H, Zenner H-P. Evaluation of speech intelligibility after prosthetic voice restoration by a standardized telephone test. In: Algaba J, editor. Surgery and prosthetic voice restoration after total and subtotal laryngectomy. Amsterdam: Elsevier; 1996; p p 183-187. de Maddalena H, Pfrang H, Schohe R, Zenner H-P. Sprachverständlichkeit und psychosoziale Anpassung bei verschiedenen Stimmrehabilitationsmethoden nach Laryngektomie. Laryngorhinootologie. 1991 Oct;70(10):562-7. Altman DG. Logistic Regression. Practical statistics for medical research. London: Chapman \& Hall; 1991; p p 351 358. an inductive approach to examine the "black box" of rehabilitation. Arch Phys Med Rehabil. 2004;85(4):678-86.

1
Van Stan JH, Roy N, Awan S, Stemple J, Hillman RE. A Taxonomy of Voice Therapy. Am J Speech-Language Pathol. 
2015;24:101-26.

American Speech-Language-Hearing Association. Evidence-based practice in communication disorders [Position Statement]. 2005.Available from: http://www.asha.org/policy/PS2005-00221/ 
Table 1 Distribution of communication techniques used in daily life

\begin{tabular}{lcccc}
\hline \multicolumn{4}{l}{ communication techniques used in daily life } \\
\hline & not at all & rarely & sometimes & often \\
\cline { 2 - 5 } oesophageal voice & 51 & 15 & 6 & 24 \\
tracheoesophageal prosthesis & 59 & 7 & 2 & 29 \\
electronic device & 68 & 11 & 7 & 14 \\
writing & 19 & 31 & 17 & 34 \\
hand signals & 21 & 24 & 31 & 24 \\
whispering & 25 & 13 & 23 & 36 \\
\hline Percent (\%) of participants in the cohort $(\mathrm{n}=124)$ using the technique \\
\hline
\end{tabular}


Table 2 Multivariate hierarchical logistic regression for objective speech intelligibility and subjective speech intelligibility.

\begin{tabular}{lll}
\hline Objective speech intelligibility & \\
\hline Parameter tested & OR $(95 \%$ Cl) & $\boldsymbol{P}$ value \\
\hline finding SLP likeable & $1.30(0.78-2.18)$ & .32 \\
age & $0.94(0.90-0.98)$ & $<.01$ \\
sex & $0.80(0.25-2.61)$ & .71 \\
education level & $1.54(0.71-3.33)$ & .27 \\
\hline
\end{tabular}

Subjective speech intelligibility

\begin{tabular}{lll}
\hline Parameter tested & OR $(\mathbf{9 5 \%} \mathbf{C l})$ & $\boldsymbol{P}$ value \\
\hline finding SLP likeable & $1.01(0.60-1.72)$ & .96 \\
age & $0.95(0.91-0.99)$ & .02 \\
sex & $0.89(0.27-2.99)$ & .86 \\
education level & $1.29(0.58-2.86)$ & .53 \\
\hline
\end{tabular}

OR, odds ratio; $\mathrm{Cl}$, confidence interval; SLP, speech-language pathologist 
Fig1 Model. Bold borders indicate the novel predictor of interest and the two outcome variables. Thin borders indicate the assumed influencing variables.

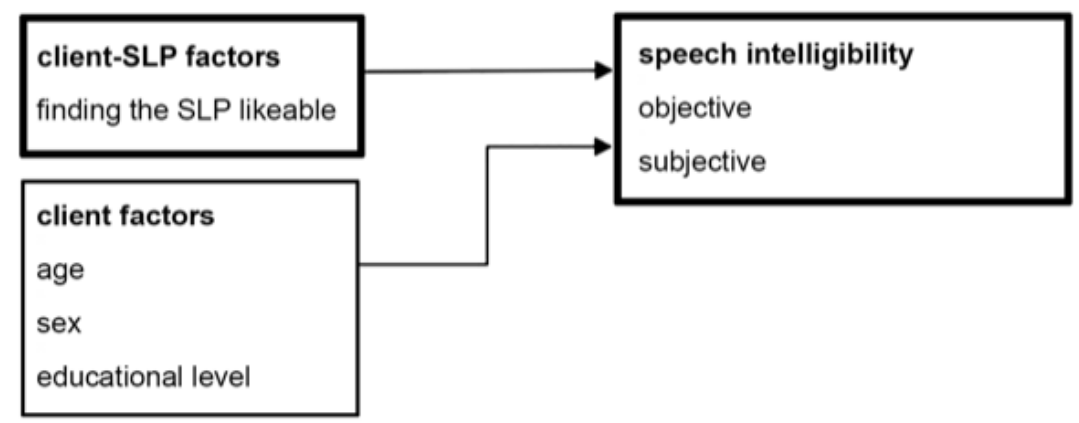

Fig. 1. Model. Bold borders indicate the novel predictor of interest and the two outcome variables. Thin borders indicate the assumed influencing variables. 